\title{
Rancangan Sumur Resapan Air Hujan sebagai Upaya Pengurangan Limpasan di Kampung Babakan, Cibinong, Kabupaten Bogor
}

(The Design of Infiltration Wells to Reduce Runoff in Babakan Village, Cibinong, Bogor Regency)

\footnotetext{
Lussiany Bahunta ${ }^{1}$ dan Roh Santoso Budi Waspodo ${ }^{1 *}$

${ }^{1}$ Departemen Teknik Sipil dan Lingkungan, Fakultas Teknologi Pertanian, Institut Pertanian Bogor. Jl. Raya Dramaga, Kampus IPB Dramaga, PO BOX 220, Bogor, Jawa Barat Indonesia
}

*Penulis korespondensi: rohsbw@yahoo.com

Diterima: 05 September 2018

Disetujui: 20 Maret 2019

\begin{abstract}
Land use change due to housing construction can indirectly damage the water catchment area. This resulted in a decrease in the area of rainwater absorption that caused rain water collected on existing drainage channels. This study aims to analyze the number and dimensions of infiltration wells in reducing the volume of inundation and determine the value of effectiveness reduction of runoff. The infiltration wells was used to collect rainwater and absorb it into the soil. Based on the calculation in Babakan Village area of 2.42 ha, with runoff coefficient of 0.4 for village character, and design rainfall of 97.36 $\mathrm{mm} /$ day, the estimated flood volume based on SNI 03-2453-2002 was 805790.30 liter or $805.79 \mathrm{~m}^{3}$. Based on the calculation, Babakan Village needed 115 infiltration wells and 76 trenches. With the infiltration wells and trenches, the total flood volume can be reduced $620.62 \mathrm{~m}^{3}$ or $77.02 \%$ of the total runoff.
\end{abstract}

Keywords: design rainfall, infiltration wells, runoff, trenches

\section{PENDAHULUAN}

Perubahan penggunaan lahan akibat pembangunan perumahan, secara tidak langsung dapat merusak kawasan resapan air. Hal ini mengakibatkan semakin berkurangnya daerah resapan air hujan yang menyebabkan air hujan terkumpul pada saluran drainase yang ada. Kondisi tersebut akan menimbulkan meningkatnya volume air permukaan yang masuk ke saluran drainase dan meluapnya air pada saluran yang dapat menyebabkan terjadinya genangan atau bahkan banjir. Perencanaan drainase perlu memperhatikan fungsi drainase yang dilandaskan pada konsep pembangunan yang berwawasan lingkungan. Konsep ini berkaitan dengan upaya konservasi sumber daya air dengan memperlambat aliran limpasan air hujan dan mengendalikan agar dapat meresap ke dalam tanah melalui bangunan resapan seperti sumur resapan.

Sumur resapan merupakan sarana untuk menampung air hujan dan meresapkannya ke dalam tanah. Air hujan yang jatuh ke atas atap rumah tidak dialirkan ke selokan atau halaman rumah, tetapi dialirkan dengan menggunakan pipa atau saluran air ke dalam sumur sehingga dapat mengurangi jumlah limpasan yang terjadi. Nilai limpasan permukaan yang lebih besar dibandingkan dengan daya serap tanah menimbulkan terjadinya genangan air sesaat setelah hujan terjadi. Genangan air yang terus-menerus terjadi akibat ketidakmampuan tanah dalam menyerapkan air hujan berakibat terjadinya banjir. Peningkatan limpasan permukaan aliran akan mengakibatkan masalah genangan dan banjir (Dwi 2008). 
Banjir di wilayah perkotaan dapat diklasifikasikan sebagai banjir akibat curah hujan lokal yang besar, banjir akibat luapan sungai, dan banjir bandang (Tingsanchali 2012).

Beberapa upaya penanganan drainase seperti normalisasi sungai dan saluran atau perbaikan dan penambahan saluran hanya dapat menanggulangi permasalahan drainase untuk jangka pendek (Suripin 2004). Penanganan yang baik seharusnya dapat menangani permasalahan drainase secara terintegrasi. Perencanaan drainase perlu memperhatikan fungsi drainase yang dilandaskan pada konsep pembangunan yang berwawasan lingkungan. Konsep ini berkaitan dengan upaya konservasi sumber daya air dengan memperlambat aliran limpasan air hujan dan mengendalikan agar dapat meresap ke dalam tanah melalui bangunan resapan baik buatan maupun alami seperti kolam tandon, sumur-sumur resapan, biopori, dan lainnya. Oleh sebab itu, diperlukan adanya penelitian di Kampung Babakan, Cibinong yang berdasarkan observasi langsung terdapat genangan bahkan banjir kecil di lokasi tersebut. Kondisi tersebut dapat menyebabkan terganggunya warga sekitar ataupun aktivitas pejalan kaki, jalan menjadi berlubang dan rusak. Maka, sumur resapan dikaji sebagai salah satu metode alternatif untuk menangani banyaknya limpasan dan terjadinya genangan di daerah yang elevasinya lebih rendah yang dapat diterima oleh masyarakat umum.

\section{METODOLOGI}

Data yang digunakan adalah data primer berupa nilai permeabilitas tanah serta data sekunder meliputi data topografi dan data hidrologi. Selain itu, penelitian ini menggunakan data curah hujan harian 10 tahun terakhir yaitu dari tahun 20082017 dan SNI 03- 2453-2002 (BSN 2002) serta data saluran drainase. Alat yang digunakan dalam penelitian yaitu laptop yang dilengkapi microsoft office, ArcGIS, AutoCad dan Google Earth Pro, alat ukur panjang (tapping), stop watch, dan bor biopori.

Penelitian diawali dengan studi literatur terkait sumur resapan, kemudian dilakukan penentuan lokasi penelitian. Pengumpulan data baik data curah hujan, data tata guna lahan maupun data karakteristik saluran drainase dilakukan di lokasi penelitian. Dari data yang diperoleh, analisis dilakukan untuk mengetahui debit rencana dan debit yang sudah terjadi di saluran drainase. Selanjutnya dilakukan perhitungan kapasitas sumur resapan dan debit rencana sehingga jumlah sumur resapan yang diperlukan dapat ditentukan. Data sekunder yang kemudian dianalisis untuk memperoleh debit rencana dan debit yang terjadi.

\section{Perhitungan Curah Hujan Rencana (R24)}

Prosedur pengolahan data dilakukan dengan perhitungan curah hujan rencana (R24). Analisis curah hujan memproses data curah hujan mentah, diolah menjadi data yang siap dipakai untuk perhitungan debit aliran. Data curah hujan yang akan dianalisis berupa kumpulan data selama 10 tahun pengamatan. Kejadian hujan merupakan proses stokastik, sehingga untuk keperluan analisa dan menjelaskan proses stokastik tersebut digunakan teori probabilitas dan analisa frekuensi (Upomo 2016). Perhitungan curah hujan rencana menggunakan data curah hujan dengan periode ulang tertentu yang dihitung dengan 4 metode distribusi frekuensi yaitu distribusi normal, distribusi log normal, distribusi log pearson III, dan distribusi Gumbel (Supriyani et al 2012). Perhitungan hujan rancangan setiap metode distribusi untuk periode ulang 
tertentu menggunakan persamaan (1), (2), (3) dan (4).

Distribusi Normal

$$
\mathrm{X}_{\mathrm{T}}=\bar{X}+\mathrm{K}_{\mathrm{T}} \mathrm{S}
$$

Distribusi Log Normal

$\mathrm{X}_{\mathrm{T}}=\log \bar{X}+\mathrm{K}_{\mathrm{T}} \mathrm{S}$

Distribusi Log Pearson III

$\log \mathrm{X}_{\mathrm{T}}=\log \overline{X+\mathrm{KS}}$

Distribusi Gumbel

$\mathrm{X}=\bar{X}+\mathrm{SK}$

Keterangan:

$X_{T}=$ Hujan rencana periode $\mathrm{T}$ tahun

$\bar{X}=$ Harga rata-rata sampel

$K=$ Faktor probabilitas

$K_{T}=$ Faktor probabilitas (dari tabel reduksi Gauss)

$S=$ Standar deviasi simpangan baku

Uji kecocokan jenis distribusi dilakukan pada keempat jenis distribusi untuk mengetahui tingkat kecocokan jenis distribusi yang digunakan dalam analisis selanjutnya (Agus et al 2013). Uji ini dilakukan dengan dua metode yaitu uji Smirnov-Kolmogorov dan uji parameter statistik. Uji Smirnov Kolmogorov digunakan untuk menentukan contoh uji dari fungsi probabilitas yang kontinu (Ayoola dan Azeez 2012). Distribusi frekuensi digunakan untuk mengetahui hubungan besarnya kejadian hidrologi ekstrim seperti banjir dengan jumlah kejadian yang telah terjadi sehingga peluang kejadian ekstrim terhadap waktu dapat diprediksi (Bhim 2012). Analisis data yang dilakukan pada keempat metode tersebut meliputi rata-rata, simpangan baku, koefisien variasi, koefisien skewness (kecondongan) dan koefisien kurtosis. Hasil yang didapat untuk keempat metode tersebut, kemudian dilakukan uji kecocokan dengan metode SmirnovKolmogorov atau uji kesesuaian nonparametrik. Uji kecocokan ini digunakan untuk menentukan nilai curah hujan rancangan dari keempat metode ditribusi frekuensi yang paling cocok digunakan di lokasi penelitian.

Penentuan periode ulang untuk hujan rancangan yang digunakan di lokasi penelitian dilakukan berdasarkan SNI 032453-2002 (BSN 2002). Periode ulang yang digunakan terdapat pada Tabel 1.

Tabel 1 Periode ulang untuk tipologi kota tertentu

\begin{tabular}{lcccc}
\hline \multirow{2}{*}{ Tipologi Kota } & \multicolumn{4}{c}{ Daerah Tangkapan Air (ha) } \\
\cline { 2 - 5 } & $\mathbf{< 1 0}$ & $\mathbf{1 0 - 1 0 0}$ & $\mathbf{1 0 1 - 5 0 0}$ & $>\mathbf{5 0 0}$ \\
\hline Kota Metropolitan & 2 tahun & $2-5$ tahun & $5-10$ tahun & $10-25$ tahun \\
Kota Besar & 2 tahun & $2-5$ tahun & $2-5$ tahun & $5-20$ tahun \\
Kota Sedang & 2 tahun & $2-5$ tahun & $2-5$ tahun & $5-10$ tahun \\
Kota Kecil & 2 tahun & 2 tahun & 2 tahun & $2-5$ tahun \\
\hline
\end{tabular}

Sumber: BSN 2002

\section{Perhitungan Tata Guna Lahan dan Koefisien Limpasan}

Penentuan luas tutupan lahan menggunakan software Google Earth dan ArcGIS 10 dengan menghitung luas tutupan lahan per DTA yang kemudian digunakan untuk menentukan besarnya nilai koefisien limpasan (C) di lokasi penelitian. Koefisien limpasan merupakan perbandingan antara limpasan dan curah hujan (Rajil et al 2011).

\section{Penentuan Nilai $\quad$ Koefisien Permeabilitas}

Permeabilitas merupakan kecepatan bergeraknya suatu cairan pada suatu media berpori dalam keadaan jenuh. Menurut Arsyad (2010), permeabilitas tanah dapat diklasifikasikan seperti yang terdapat pada Tabel 2. Dalam pengukuran 
kapasitas atau laju infiltrasi digunakan model Philips, Geonadi et al (2012) menjelaskan bahwa model infiltrasi Philips cukup sesuai digunakan untuk prediksi limpasan permukaan. Model tersebut secara empiris dituliskan dalam persamaan (5).

$$
f(t)=\frac{1}{2} \mathrm{~s} x t^{-0.5}+K
$$

Keterangan :

$f(t)=$ Fungsi laju infiltrasi terhadap waktu $(\mathrm{cm} / \mathrm{menit})$

$S=$ Daya serap tanah $(\%)$

$t$ = waktu (menit)

$K=$ Konduktivitas hidrolik/permeabiltas tanah $(\mathrm{cm} / \mathrm{jam})$

Tabel 2 Klasifikasi kemampuan permeabilitas tanah

\begin{tabular}{cc}
\hline $\begin{array}{c}\text { Permeabilitas } \\
\text { Tanah }\end{array}$ & Nilai (cm/jam) \\
\hline Lambat & $<0.5$ \\
Agar Lambat & $0.5-2.0$ \\
Sedang & $2.0-6.25$ \\
Agak Cepat & $6.25-12.5$ \\
Cepat & $>12.5$ \\
\hline
\end{tabular}

Perhitungan Volume Andil Banjir Total

Sistem penampungan dan peresapan air hujan merupakan suatu sistem drainase untuk mengurangi aliran permukaan akibat hujan. Konsep dasar sistem ini adalah memberi kesempatan pada air hujan untuk meresap ke dalam tanah dengan cara menampung air tersebut pada suatu sistem resapan. Beberapa sistem penampungan dan peresapan air hujan diantaranya adalah sumur resapan (berupa sumur resapan individu, kolam resapan, dan parit berorak) atau lubang biopori.

Adapun tata cara perencanaan sumur resapan air hujan mengacu pada SNI 03-2453-2002. Perhitungan volume andil banjir dan jumlah sumur yang dibutuhkan dilakukan dengan menggunakan persamaan (6) sampai persamaan (10).

$V a b=0.85 \times C \times A \times R$

Keterangan :

$V a b=$ Volume andil banjir $\left(\mathrm{m}^{3}\right)$

$C=$ Koefisien limpasan

$A=$ Luas daerah pengaliran $\left(\mathrm{m}^{2}\right)$

$R \quad=$ Tinggi hujan harian rata-rata (mm/hari)

$\operatorname{Vrsp}=\left(\frac{t e}{24}\right) \times A \times K$

Keterangan :

$V r s p=$ Volume air hujan yang meresap $\left(\mathrm{m}^{3}\right)$

te $=$ Durasi hujan $=0.9$ R0.92 $/ 60$ (jam)

$A=$ Luas permukaan sumur $\left(\mathrm{m}^{2}\right)$

$K=$ Koefisien permeabilitas tanah (m/hari)

Vstorasi $=$ Vab - Vrsp

Htotal $=\frac{\text { Vstorasi }}{A h}$

$\mathrm{n}=\frac{\text { Htotal }}{\text { Hrencana }}$

Keterangan :

Vstorasi = Volume penampungan $\left(\mathrm{m}^{3}\right)$

Htotal = Kedalaman total sumur (m)

Hrencana $=$ Kedalaman yang direncanakan $(\mathrm{m})$

$A h \quad=$ Luas alas sumur $\left(\mathrm{m}^{2}\right)$

$n \quad=$ Jumlah sumur yang

dibutuhkan

\section{Perencanaan Dimensi dan Jumlah Bangunan Resapan}

Perencanaan desain bangunan resapan mengikuti tata cara perencanaan sumur resapan air hujan mengacu pada SNI 03-2453-2002 (BSN 2002). Banyaknya jumlah bangunan resapan ditentukan berdasarkan volume andil 
banjir yang akan ditampung dan diresapkan ke dalam bangunan resapan. Besarnya nilai efektivitas pengurangan limpasan didapat dari jumlah limpasan yang mampu diserap oleh bangunan resapan dibagi volume andil banjir total.

\section{Perhitungan Rencana Anggaran Biaya (RAB)}

Setelah Perhitungan rencana anggaran biaya ini hanya mencakup harga bahan. Perhitungan RAB mengacu pada
SNI 6897-2008 (BSN 2008a) dan SNI 7394-2008 (BSN 2008b).

\section{HASIL DAN PEMBAHASAN}

\section{Analisis Hujan dan Volume Andil Banjir}

Analisis hujan menggunakan data curah hujan harian maksimum selama 10 tahun dari tahun 2008 hingga 2017 dari Stasiun Klimatologi BMKG Kabupaten Bogor. Data curah hujan harian maksimum disajikan pada Tabel 3.

Tabel 3 Data curah hujan harian maksimum 10 tahun (mm/hari)

\begin{tabular}{cccccccccccccc}
\hline \multirow{2}{*}{ Tahun } & \multicolumn{10}{c}{ Bulan } \\
\cline { 2 - 12 } & Jan & Feb & Mar & Apr & Mei & Jun & Jul & Ags & Sep & Okt & Nov & Des & Maks \\
\hline 2008 & 78 & 70 & 62 & 80 & 39 & 19 & 65.6 & 39 & 43 & 65 & 58 & 48 & 80 \\
2009 & 89 & 84 & 80 & 76 & 64 & 47 & 67 & 58.1 & 17 & 43 & 50 & 57.5 & 89 \\
2010 & 56 & 115 & 79 & 66.5 & 56 & 119 & 33 & 69 & 70 & 78 & 57 & 38 & 119 \\
2011 & 99 & 65 & 25 & 34 & 30 & 60 & 35.5 & 57.5 & 19 & 53 & 118 & 58 & 118 \\
2012 & 82 & 43 & 36 & 49 & 39 & 45 & 25 & 32 & 36 & 50 & 89 & 62 & 89 \\
2013 & 100 & 70 & 130 & 60 & 92 & 35 & 76 & 34 & 20 & 36 & 45 & 116 & 130 \\
2014 & 192.8 & 95.7 & 52.5 & 99.2 & 52.4 & 84.6 & 70.5 & 35.3 & 32.4 & 21.5 & 86.5 & 109.9 & 192.8 \\
2015 & 41.5 & 71.8 & 67.8 & 45.1 & 44 & 76 & 86 & 54 & 21 & 67 & 86.6 & 44.1 & 86.6 \\
2016 & 45.5 & 74.4 & 54.4 & 54.5 & 42.2 & 80.5 & 55.3 & 19.4 & 48.1 & 69 & 79.4 & 17 & 80.5 \\
2017 & 58.4 & 63.7 & 66.2 & 51.6 & 47.5 & 34.5 & 37.9 & 24 & 11.4 & 40.3 & 90 & 48.2 & 90 \\
\hline
\end{tabular}

Sumber BMKG Kabupaten Bogor

Tabel 3 menunjukkan bahwa curah hujan harian maksimum tertinggi setiap tahunnya berkisar antara $80 \mathrm{~mm}$ hingga $192.8 \mathrm{~mm}$. Curah hujan harian maksimum tertinggi terjadi pada bulan Januari tahun 2014 sebesar $192.8 \mathrm{~mm}$. Kejadian curah hujan ekstrim tersebut terjadi hanya dalam periode 3 sampai 5 tahun sekali. Data curah hujan tersebut diolah dengan analisis frekuensi, setelah ditentukan nilai curah hujan maksimum harian untuk tiap tahunnya. Tujuan analisis frekuensi data hidrologi yaitu untuk mengetahui peristiwa-peristiwa ekstrim (R24) yang berkaitan dengan frekuensi kejadiannya melalui penerapan distribusi kemungkinan (Suripin 2003). Analisis distribusi frekuensi mencakup distribusi normal, distribusi Log normal, distribusi LogPerson III, dan distribusi Gumbel untuk periode ulang $2,5,10,20,25$, dan 50 tahun.

Kemudian dilakukan penentuan curah hujan rancangan menggunakan data curah hujan maksimum harian rata-rata selama 10 tahun dari Stasiun Badan Meteorologi, Klimatologi dan Geofisika Kabupaten Bogor. Data curah hujan yang telah diperoleh kemudian dianalisis dengan empat metode distribusi frekuensi yaitu metode Normal, Log Normal, Log Pearson III dan Gumbel. Hasil dari keempat metode tersebut dilakukan uji kecocokan menggunakan uji Smirnov- 
Kolmogorov dan analisis parameter penelitian. Adapun nilai curah hujan statistik sehingga dapat diketahui rancangan untuk berbagai periode ulang distribusi frekuensi untuk hujan rancangan tertentu disajikan pada Tabel 4.

yang sesuai digunakan di lokasi

Tabel 4 Hujan rencana untuk periode ulang tertentu

\begin{tabular}{ccccc}
\hline \multirow{2}{*}{$\begin{array}{c}\text { Periode } \\
\text { Ulang } \\
\text { (T tahun) }\end{array}$} & Normal & Log Normal & $\begin{array}{c}\text { Log Person } \\
\text { III }\end{array}$ & Gumbel \\
\cline { 2 - 5 } & 107.49 & 103.41 & 97.36 & 102.77 \\
2 & 136.77 & 130.75 & 126.20 & 144.39 \\
5 & 152.11 & 147.85 & 150.26 & 171.94 \\
10 & 167.10 & 166.72 & 186.72 & 206.76 \\
25 & 178.95 & 183.33 & 218.72 & 232.58 \\
50 & & & & \\
\hline
\end{tabular}

Berdasarkan uji kecocokan menggunakan uji Smirnov-Kolmogorov dan analisis parameter statistik metode yang dipakai untuk analisis frekuensi adalah metode Log Person III, nilai curah hujan rencana dengan periode ulang dua tahun, yaitu sebesar $97.36 \mathrm{~mm} / \mathrm{hari}$. Berdasarkan perhitungan volume andil banjir total wilayah kampung babakan seluas 2.42 ha dengan koefisien limpasan sebesar 0.4 untuk karakter perkampungan, dan curah hujan rencana sebesar 97.36 $\mathrm{mm} / \mathrm{hari}$. Maka didapatkan perkiraan volume andil banjir bedasarkan SNI 032453-2002 yaitu sebesar 805790.30 liter atau setara dengan $805.79 \mathrm{~m}^{3}$. Sedangkan untuk volume andil banjir atap rumah dapat dilihat pada Tabel 5.

Tabel 5 Volume Andil Banjir Atap Rumah

\begin{tabular}{cccccc}
\hline $\mathbf{C}$ & $\mathbf{I}(\mathbf{m m} / \mathbf{h a r i})$ & Luas Atap $\left(\mathbf{m}^{2}\right)$ & Jumlah Rumah & Vab $\left(\mathbf{m}^{3}\right)$ & Vab total $\left(\mathbf{m}^{3}\right)$ \\
\hline 0.95 & 97.36 & 60 & 5 & 4.74 & 23.72 \\
0.95 & 97.36 & 70 & 3 & 5.54 & 16.61 \\
0.95 & 97.36 & 80 & 5 & 6.33 & 31.63 \\
0.95 & 97.36 & 90 & 5 & 7.12 & 35.59 \\
0.95 & 97.36 & 100 & 15 & 7.91 & 118.62 \\
0.95 & 97.36 & 130 & 8 & 10.28 & 82.24 \\
0.95 & 97.36 & 150 & 4 & 11.86 & 47.45 \\
0.95 & 97.36 & 180 & 6 & 14.23 & 85.41 \\
0.95 & 97.36 & 200 & 4 & 15.82 & 63.26 \\
\hline Jumlah & \multicolumn{5}{c}{} \\
\hline
\end{tabular}

Berdasarkan tabel 5 terlihat bahwa volume andil banjir tiap rumah berbedabeda, semakin luas atap rumah maka semakin besar pula volume andil banjir yang dihasilkan, sehingga setiap rumah membutuhkan jumlah sumur resapan yang berbeda-beda. Berdasarkan Peraturan Menteri Negara Lingkungan Hidup 
Nomor 12 Tahun 2009 tentang resapan. Setelah dilakukan penentuan pemanfaatan air hujan, jumlah sumur jenis distribusi yang digunakan, maka resapan dengan luas atap $50 \mathrm{~m}^{2}$ adalah 1 dilakukan penentuan intensitas hujan unit dan setiap tambahan $25-50 \mathrm{~m}^{2}$ luas rancangan menggunakan rumus atap diperlukan tambahan 1 unit sumur mononobe, dapat dilihat pada Gambar 1.

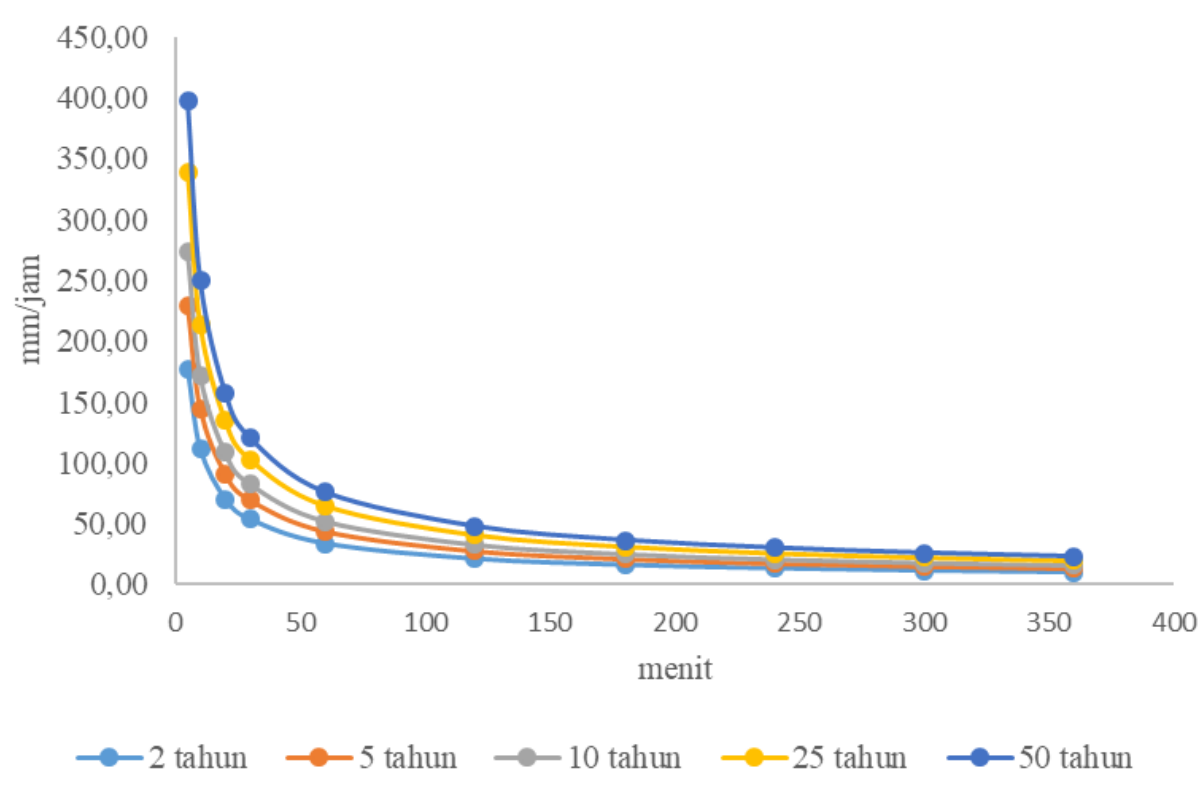

Gambar 1 Hasil analisis hujan rancangan

Berdasarkan hasil tersebut menunjukan bahwa semakin besar periode ulang maka intensitas hujan rancangan yang dihasilkan semakin besar, sehingga jika pembuatan sumur resapan menggunakan periode ulang yang besar maka menghasilkan sumur resapan yang lebih dalam. Berbanding terbalik dengan durasi hujan, semakin lama durasi hujan maka menghasilkan intensitas hujan rendah, karena biasanya hujan deras berlangsung pada waktu singkat sehingga konsentrasi hujan yang tinggi terdapat pada awal terjadinya hujan.

\section{Permeabilitas Tanah}

Pengukuran permeabilitas tanah dilakukan di 5 titik yang berbeda, namun dari keseluruhan sampel didapatkan nilai yang cukup seragam dengan nilai rata-rata sebesar $0.000968 \mathrm{~cm} /$ detik atau setara dengan $3.48 \mathrm{~cm} / \mathrm{jam}$. Hal ini terjadi karena cakupan wilayah penelitian tidak begitu luas dan lokasi penelitian dibangun dengan melakukan pemadatan tanah terlebih dahulu. Berdasarkan hasil pengujian, jika dibandingkan dengan kelompok permeabilitas tanah menurut Arsyad (2010), maka tanah di Kampung Babakan termasuk kedalam tanah dengan permeabilitas sedang. Hal ini juga sesuai dengan syarat permeabilitas tanah yang dapat digunakan untuk sumur resapan menurut Suripin (2004).

Pengukuran permeabilitas dilakukan dengan membuat lubang tanah menggunakan bor biopori berdiameter 10 $\mathrm{cm}$ dan kedalaman $30 \mathrm{~cm}$. Lubang tersebut diisi air sampai penuh dan dicatat waktu penurunan muka air tanahnya. Pengukuran ini dilakukan sebanyak mungkin hingga waktu penurunan muka air tanah mendekati konstan. Hasil pengukuran yang telah didapat diolah ke 
dalam Software Ms. Excel yang kemudian dibandingkan dengan model Infiltrasi Philips (Persamaan 5). Kondisi lahan secara umum merupakan daerah dengan bangunan terpencar sehingga daya resap tanah di lokasi penelitian diasumsikan sebesar 0.3 (Tabel 4). Perhitungan dilakukan dengan trial and error nilai permeabilitas tanah yang ada pada model infiltrasi Philips. Berdasarkan perhitungan yang telah dilakukan, didapatlah kurva perbandingan nilai laju infiltrasi terukur dan model infiltrasi Philips seperti pada Gambar 2.

Grafik pada Gambar 2 menunjukkan bahwa nilai laju infiltrasi hasil pengukuran dan perhitungan dengan model infiltrasi Philips hampir berimpit saat keadaan tanah mulai jenuh setelah selang waktu tertentu. Hasil dari grafik tersebut dapat diketahui besarnya nilai permeabilitas tanah yang dapat digunakan untuk merencanakan dan merancang sumur resapan air hujan.

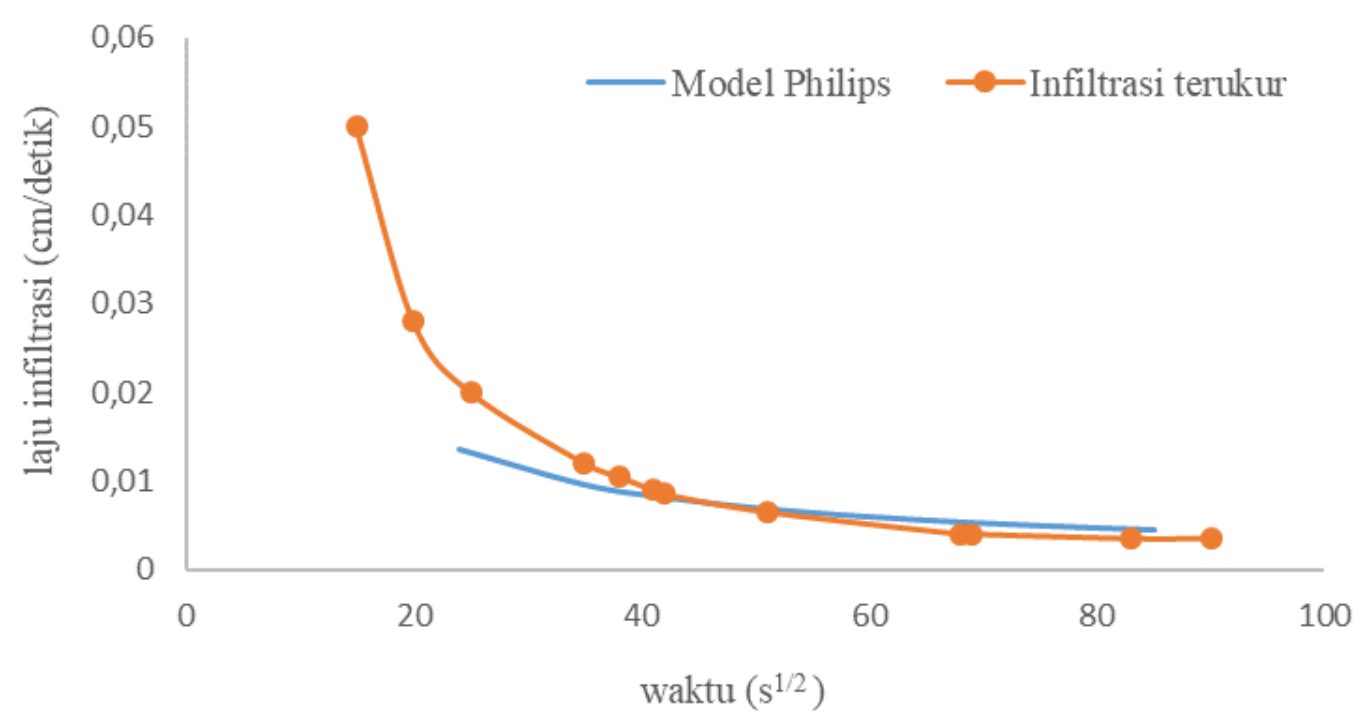

Gambar 2 Laju infiltrasi dengan model infiltrasi Philips dan pengukuran

\section{Sumur Resapan dan Parit Berorak}

Berdasarkan hasil digitasi melalui Google Earth Pro dan Arcgis terdapat 55 rumah di kampung babakan, RW 05 dengan ukuran atap yang berbeda-beda yaitu $60 \mathrm{~m}^{2}, 70 \mathrm{~m}^{2}, 80 \mathrm{~m}^{2}, 90 \mathrm{~m}^{2}, 100 \mathrm{~m}^{2}$, $130 \mathrm{~m}^{2}, 150 \mathrm{~m}^{2}, 180 \mathrm{~m}^{2}$ dan $200 \mathrm{~m}^{2}$. Direncanakan sumur resapan dengan diameter sebesar $1.4 \mathrm{~m}$ dan kedalaman 2.5 $\mathrm{m}$, didapatkan volume resapan sebesar $0.44 \mathrm{~m}^{3}$. Berdasarkan hasil tersebut maka jumlah sumur resapan dapat dilihat pada Tabel 6.
Berdasarkan hasil perhitungan, total sumur resapan yang perlu dibuat sebanyak 115 buah. Berdasarkan hasil pengamatan, rumah di kampung babakan memiliki pekarangan yang cukup luas, sehingga dapat dibangun sumur resapan tiap rumah karena sudah memenuhi persyaratan jarak yang telah ditetapkan pada SNI 03-2453-2002 yaitu jarak antara sumur resapan dan septic tank minimal 5 meter, jarak antara sumur resapan dan sumur gali berjarak minimal 3 meter. Selain itu jarak antara sumur resapan dengan pondasi bangunan lainnya seperti rumah atau pagar rumah minimal $1 \mathrm{~m}$. 
Tabel 6 Total Sumur Resapan

\begin{tabular}{cccccc}
\hline $\begin{array}{c}\text { Luas atap } \\
\left(\mathbf{m}^{2}\right)\end{array}$ & $\begin{array}{c}\text { Vstorasi } \\
\left(\mathbf{m}^{\mathbf{3}}\right)\end{array}$ & $\begin{array}{c}\text { Kedalaman } \\
\text { Total }(\mathbf{m})\end{array}$ & $\begin{array}{c}\text { Jumlah } \\
\text { rumah }\end{array}$ & $\begin{array}{c}\text { Jumlah Sumur } \\
\text { setiap rumah }\end{array}$ & $\begin{array}{c}\text { Total sumur } \\
\text { resapan }\end{array}$ \\
\hline 60 & 4.30 & 2.80 & 5 & 1 & 5 \\
70 & 5.09 & 3.31 & 3 & 1 & 3 \\
80 & 5.89 & 3.82 & 5 & 1 & 5 \\
90 & 6.68 & 4.34 & 5 & 2 & 10 \\
100 & 7.47 & 4.85 & 15 & 2 & 30 \\
130 & 9.84 & 6.39 & 8 & 2 & 16 \\
150 & 11.42 & 7.42 & 4 & 3 & 12 \\
180 & 13.79 & 8.96 & 6 & 3 & 18 \\
200 & 15.37 & 9.99 & 4 & 4 & 16 \\
\hline
\end{tabular}

115

\section{Direncanakan sumur resapan sumur dibuat dari plat beton bertulang} dengan diameter sumur sebesar $1.4 \mathrm{~m}$, dengan tebal $10 \mathrm{~cm}$ campuran semen, kedalaman sumur sebesar $2.5 \mathrm{~m}$ sehingga pasir, kerikil (perbandingan 1:2:3). diperoleh luas alas sumur sebesar $1.54 \mathrm{~m}^{2}$, Dinding sumur digunakan batu bata merah luas dinding sumur sebesar $10.99 \mathrm{~m}^{2}$ dan campuran semen dan pasir tanpa di plester luas permukaan total sebesar $12.53 \mathrm{~m}^{2}$ dan (perbandingan 1:5) yang disusun berongga didapatkan volume resapan sebesar 0.44 dengan jarak rongga adalah $10 \mathrm{~cm}$. $\mathrm{m}^{3}$. Berdasarkan perhitungan, maka Konstruksi untuk pengisi sumur bagian volume penampungan total sumur yang bawah digunakan batu pecah ukuran 10dibutuhkan untuk rumah dengan ukuran atap $60 \mathrm{~m}^{2}$ sebesar $4.3 \mathrm{~m}^{3}$ dengan kedalaman sumur total $2.8 \mathrm{~m}$. Karena telah direncanakan dimensi sumur, maka jumlah sumur yang dibutuhkan di setiap rumah dengan ukuran atap $60 \mathrm{~m}^{2}$ adalah 1 sumur. Sedangkan volume penampungan total sumur yang dibutuhkan untuk rumah dengan ukuran atap $200 \mathrm{~m}^{2}$ sebesar 15.37 $\mathrm{m}^{3}$ dengan kedalaman sumur total $9.99 \mathrm{~m}$, maka jumlah sumur yang dibutuhkan di setiap rumah dengan ukuran atap $200 \mathrm{~m}^{2}$ adalah 4 sumur. Untuk perhitungan jumlah sumur resapan pada luas atap lainnya dapat dilihat pada tabel 7 . Suprayogi et al.(2012) menjelaskan bahwa pada kasus luas atap yang lebih dari 100 $\mathrm{m}^{2}$ dapat dibuat sumur resapan dengan model paralel.

Perancangan sumur resapan terdiri dari penutup sumur, dinding sumur dan pengisi sumur. Untuk konstruksi penutup $20 \mathrm{~cm}$ dan ijuk. Hal ini difungsikan untuk meredam energi aliran air yang mengalir dari atap sehingga tidak merusak kontruksi bangunan sumur. Pengaliran air dari atap ke dalam sumur resapan digunakan pipa PVC berdiameter 110 $\mathrm{mm}$. Selain itu, perancangan sumur resapan juga dihubungkan melalui pipa penyalur ke saluran drainase untuk membuang kelebihan air apabila air hujan dari atap tidak mampu ditampung oleh sumur resapan. Pembuatan sumur resapan merupakan salah satu cara yang efektif untuk meningkatkan kapasitas infiltrasi lahan, yang selanjutnya dapat menambah cadangan air tanah. Selain itu, sumur resapan berfungsi untuk mengurangi volume dan kecepatan aliran permukaan sehingga menurunkan puncak banjir (Fakhrudin 2010).

Parit berorak merupakan sumur resapan yang meresapkan air melalui 
parit-parit yang didalamnya diberi sumursumur (rorak) penampung air. Parit berorak juga merupakan sumur resapan kolektif dengan jenis sumur resapan dangkal. Direncanakan pembuatan parit berorak karena dengan hanya dibangun sumur resapan individu di beberapa rumah tentunya belum begitu efektif dalam mengurangi debit limpasan yang terjadi. Dimensi rorak yang direncanakan yaitu dengan kedalaman $2 \mathrm{~m}$ serta panjang dan lebar alas $0.8 \mathrm{~m}$ disesuaikan dengan ukuran parit yang sudah ada dan jarak antara rorak $5 \mathrm{~m}$. Luas alas rorak adalah $0.64 \mathrm{~m}^{2}$ dan luas dinding rorak $6.4 \mathrm{~m}^{2}$. Berdasarkan hasil pehitungan didapatkan nilai volume resapan sebesar $0.25 \mathrm{~m}^{3}$ dan setiap rorak dalam parit dapat mengurangi volume andil banjir sebesar $1.53 \mathrm{~m}^{3}$. Drainase saluran utama di Kampung babakan sepanjang $439 \mathrm{~m}$, sehingga banyaknya rorak yang dapat dibangun sekitar 76 rorak dan dapat mengurangi volume andil banjir sebesar $116.09 \mathrm{~m}^{3}$. Konstruksi parit berorak secara umum tidak berbeda jauh dengan sumur resapan yang dibangun untuk meresapkan limpasan dari atap. Perbedaannya hanya pada bagian penutup atas, untuk sumur resapan menggunakan plat beton bertulang sedangkan parit berorak menggunakan plat besi penyaring dengan tujuan agar aliran air pada saluran dapat langsung masuk ke rorak

\section{Efektivitas Resapan}

Berdasarkan hasil perhitungan yang telah dilakukan total volume andil banjir yang dapat dikurangi dengan adanya sumur resapan dan parit berorak adalah sebesar $620.62 \mathrm{~m}^{3}$. Volume andil banjir total Kampung Babakan sebesar $805.79 \mathrm{~m}^{3}$ maka sumur resapan dan parit berorak dapat mengurangi $77.02 \%$ dari total limpasan yang terjadi. Adapun sisa limpasan sebanyak $22.98 \%$ atau sebesar
$185.17 \mathrm{~m}^{3}$ akan dialirkan melalui saluran drainase yang sudah ada. Kapasitas volume total saluran drainase yang sudah ada di lokasi penelitian adalah sebesar $702.4 \mathrm{~m}^{3}$. Jumlah tersebut cukup untuk menampung sisa limpasan yang tidak mampu diserap.

Berdasarkan tujuan awal penelitian yaitu untuk pengurangan limpasan, rancangan sumur resapan dapat dikatakan efektif dalam mengurangi total limpasan. Meskipun tidak semua limpasan dapat diserap ke dalam tanah. Namun bangunan resapan ini mampu menambah waktu tampung air untuk meresap ke dalam tanah. Selain itu penerapan konsep ini juga berhasil mengurangi lebih dari $50 \%$ limpasan total yang terjadi di wilayah penelitian.

\section{Rencana Anggaran Biaya (RAB)}

Pembuatan rencana anggaran biaya dibuat untuk mengetahui perkiraan biaya pembuatan sumur resapan. Besarnya biaya yang diperlukan untuk membuat 1 buah sumur resapan type II adalah sebesar Rp. 735.000 terdiri dari pekerjaan persiapan, pekerjaan tanah seperti galian tanah, galian tanah saluran hujan, urugan tanah dan meratakan tanah, kemudian pekerjaan sumur resapan serta pekerjaan perpipaan.

\section{KESIMPULAN}

Berdasarkan perhitungan volume andil banjir total di wilayah Kampung Babakan seluas 2.42 ha dengan koefisien limpasan sebesar 0.4 untuk karakter perkampungan dan curah hujan rencana $97.36 \mathrm{~mm} / \mathrm{hari}$ sebesar 805790.30 liter atau setara dengan $805.79 \mathrm{~m}^{3}$. Berdasarkan hasil perhitungan, total sumur resapan yang perlu dibuat sebanyak 115 buah serta parit berorak sebanyak 76 buah. Konstruksi penutup sumur dibuat dari plat beton bertulang dengan tebal 10 $\mathrm{cm}$ campuran semen, pasir, kerikil 
(perbandingan 1:2:3). Dinding sumur digunakan batu bata merah campuran semen dan pasir tanpa di plester (perbandingan 1:5) yang disusun berongga dengan jarak rongga adalah $10 \mathrm{~cm}$. Dengan adanya sumur resapan dan parit berorak volume andil total dapat berkurang sebesar $620.62 \mathrm{~m}^{3}$ atau dapat mengurangi $77.02 \%$ dari total limpasan yang terjadi.

\section{DAFTAR PUSTAKA}

Agus HP, Mahendra AM, Fifi S. 2013. Perencanaan dan studi pengaruh sistem drainase Marvell City terhadap saluran kalibokor di Kawasan NgagelSurabaya. Jurnal Teknik POMITS. 1(1) : 1-6.

Arsyad S. 2010. Konservasi Tanah dan Air. Edisi Revisi. Bogor (ID): IPB Press

Ayoola FJ, Azeez OB. 2012. Fitting the statistical distribution for daily rainfall in Ibadan, based on chi-square and Kolmogorov-Smirnov goodness-of-fit tests. European Journal of Business and Management. 4(17): 62-70. ISSN: 2222-1905.

Azis A, Faisal Z, Yusuf H. 2016. Konservasi air tanah melalui pembuatan sumur resapan air hujan di Kelurahan Maradekaya Kota Makasar. Jurnal INTEK. 3(2):87-90.

Bhim S, Deepak R, Amol V, Jitendra S. 2012. Probability analysis for estimation of annual one day maximum rainfall of Jhalarapatan area of Rajasthan, India. Plant Archives. 12(2) : 1093-1100. ISSN : 0972-5210.

[BSN] Badan Standardisasi Nasional. 2002. Tata Cara Perencanaan Sumur Resapan Air Hujan Untuk Lahan Pekarangan. SNI 03-2453-2002. Jakarta (ID): BSN.

[BSN] Badan Standardisasi Nasional. 2008a. Tata Cara Perhitungan Harga Satuan Pekerjaan Dinding untuk Konstruksi Bangunan Gedung dan
Perumahan. SNI 6897-2008. Jakarta (ID): BSN.

[BSN] Badan Standardisasi Nasional. 2008b. Tata Cara Perhitungan Harga Satuan Pekerjaan Beton untuk Konstruksi Bangunan Gedung dan Perumahan. SNI 7394-2008. Jakarta (ID): BSN.

Dwi T, Sabariah M, M Baharudin R. 2008. A study on artificial recharge well as a part of drainge system and water supply in UHTM. National Seminar on Environment, Development \& Sustainability. Selangor (MY).1 : 106111.

Fakhrudin M. 2010. Kajian sumur resapan sebagai pengendali banjir dan kekeringan di Jabodetabek. LIMNOTEK. 17(1):8-16.

Geonadi S, Mawardi M, Ritawati S. 2012. Kesesuaian model infiltrasi philips untuk prediksi limpasan permukaan menggunakan metode bilangan kurva. AGRITECH. 32(3):331.

Ihsan M, Setiawan B I. 2014. Analisis hujan, debit puncak limpasan, dan volume genangan di sekitar gedung Graha Widya Wisuda-FEMA, Kampus IPB Dramaga Bogor. JTEP. 1(1):1-11.

Iriani, Kurnia. 2013. Perencanaan sumur resapan air hujan untuk konservasi air tanah di daerah permukiman (studi kasus di Perumahan RT.II, III, dan IV Perumnas Lingkar Timur Bengkulu). Jurnal Inersia. 5 (1).

Kusnaedi. 2006. Sumur Resapan untuk Permukiman Perkotaan dan Perdesaan. Jakarta (ID): Penebar Swadaya

Latief YA. 2009. Analisis curah hujan untuk membuat kurva IDF pada Sub DAS Metro. Jurnal Skripsi. 11:1. Universitas Muhammadiyah Malang.

Ponce VM. 1989. Engineering Hydrology: Principles and Practices. New Jersey (US) : PrenticeHall

Pontoh NK. 2005. Hubungan perubahan penggunaan lahan dengan limpasan air permukaan studi kasus Kota Bogor. 
Jurnal Perencanaan Wilayah dan Kota. 16(3): 44-56.

Rachman AR, Suhardjono, Juwono PT. 2014. Studi pengendalian banjir di Kecamatan Kepanjen dengan sumur resapan. Jurnal Teknik Pengairan. 5 (1): 79-90.

Rajil P, Uma E, Shyla J. 2011. Rainfall-runOff analysis of a compacted area. Agricultural Engineering International: The CIGR Journal. 13 (1): 1-11.

Saleh C. 2011. Kajian penanggulangan limpasan permukaan dengan menggunakan sumur resapan (studi kasus di di daerah Perumnas Made Kabupaten Lamongan). Jurnal Teknik Sipil. 9(2):116-124.

Sjarif L. 2003. Penentuan karakteristik akuifer sumur air tanah melalui uji pemompaan (pumping test) dengan metode CooperJacob di Leuwikopo, Dramaga [skripsi]. Bogor (ID): Institut Pertanian Bogor.

Soemarto, CD. 1987. Hidrologi Teknik. Surabaya (ID): Usaha Nasional.

Sunjoto S.1989. Teknik Konservasi Air pada Kawasan Permukiman.Yogyakarta (ID): LPM-UGM

Suprayogi S, Werdiningsih. 2012. Rancangan dimensi sumur resapan untuk konservasi air tanah di kompleks Tambakbayan, Sleman, Yogyakarta. Jurnal Indonesia. 1(3):482-491.

Supriyani E, Bisri M, Dermawan V. 2012. Studi pengembangan sistem drainase perkotaan berwawasan lingkungan. Jurnal Teknik Pengairan. 3(2):112-121.

Suripin. 2004. Hidrolika. Semarang (ID): Jurusan Teknik Sipil FT Undip.

Tingsanchali T. 2012. Urban flood disaster management. Procedia Engineering. 32: 25-37. doi : 10.1016 .

Upomo TC, Kusumawardani R. 2016. Pemilihan distribusi probabilitas pada analisa hujan dengan metode goodness of fit test. Jurnal Teknik Sipil dan Perencanaan. 18(2):139-148. 